Karlsruhe Institute of Technology

\begin{tabular}{|c|c|c|}
\hline Title: & \multicolumn{2}{|c|}{ A multi-string photovoltaic inverter for thin-film or back-side contacted solar modules } \\
\hline Authors: & \multicolumn{2}{|c|}{ Mario Gommeringer, Alexander Schmitt, Michael Braun } \\
\hline Institute: & \multicolumn{2}{|c|}{$\begin{array}{l}\text { Karlsruhe Institute of Technology (KIT) } \\
\text { Elektrotechnisches Institut (ETI) }\end{array}$} \\
\hline Type: & \multicolumn{2}{|c|}{ Conference Proceedings } \\
\hline Published at: & $\begin{array}{l}\text { The } 8^{\text {th }} \text { IET Internation } \\
\text { (PEMD) } 2016 \\
\text { Date of Conference: } \\
\text { Conference Location: } \\
\text { Publisher: } \\
\text { ISBN: }\end{array}$ & $\begin{array}{l}\text { al Conference on Power Electronics, Machines and Drives } \\
\text { 19. April } 2016-21 \text {. April } 2016 \\
\text { Glasgow, Scotland, UK } \\
\text { The Institution of Engineering and Technology (IET) } \\
\text { 978-1-78561-189-6 }\end{array}$ \\
\hline
\end{tabular}




\title{
A multi-string photovoltaic inverter for thin-film or back-side contacted solar modules
}

\author{
Mario Gommeringer, Alexander Schmitt, Michael Braun \\ Karlsruhe Institute of Technology \\ Institute of Electrical Engineering / Elektrotechnisches Institut (ETI) \\ Kaiserstr. 12, 76131 Karlsruhe, Germany \\ mario.gommeringer@kit.edu
}

Keywords: Photovoltaics, MPP tracking, DC-AC converter, 3-level inverter

\begin{abstract}
Photovoltaic inverters are widely used to feed solar generated power into the public grid. Inverter topologies have to be carefully chosen, depending on the type and on the power of the solar generator. A new transformerless, three-level photovoltaic inverter circuit for multiple strings is investigated in this paper. It allows an individual MPP tracking of each string without needing a full scale boost converter for each input. Furthermore, either the positive poles or the negative poles of the strings can be connected to the neutral conductor N. Therefore, the topology is especially suited for thin-film or back-side contacted solar modules.
\end{abstract}

\section{Introduction}

Depending on the configuration of the solar generator, photovoltaic inverters have to fulfill several requirements. If partial shading occurs in multi-string systems, an individual maximum power point (MPP) tracking of every string is very advantageous to maximize the energy yield. Furthermore, it may be required to connect one pole of the strings to the neutral conductor $\mathrm{N}$. Connecting the negative poles to $\mathrm{N}$ can prevent thin-film solar modules from corrosion of the transparent conductive oxide (TCO) [1]. Connecting the positive poles to $\mathrm{N}$ can lead to a higher efficiency if back-side contacted solar modules are used [2]. Last but not least some grid codes, e.g. [3] require, that certain photovoltaic inverters must be able to deliver reactive power. A new transformerless circuit, which fulfills these requirements is shown in Fig. 1. A basic description can be found in [4]. This contribution presents a detailed circuit description, an appropriate control system and experimental results.

\section{Function of the circuit}

The circuit of Fig. 1 consists of $M$ input half-bridges and a common inverter section [4]. They are interconnected at X1X3 with a split DC-link, consisting of the capacitors C1 and $\mathrm{C} 2$. Another capacitor $\mathrm{C} 3$ can be added optionally. The input half-bridges are built up with two transistors T $1 x$ and T $2 x$ $(x \in\{1,2 . . M\})$. They are used to control the string voltages $u_{\mathrm{G} x}$ in the range $u_{\mathrm{C} 2}<u_{\mathrm{G} x}<u_{\mathrm{C} 1}+u_{\mathrm{C} 2}$. Furthermore, they spilt the string currents $i_{\mathrm{G} x}$ into the currents $i_{\mathrm{E} 1}$ and $i_{\mathrm{E} 2}$. The inverter section on the right side of Fig. 1 is built up with the transistors T3-T7 and is similar to the single string topology of [5-7]. The positive poles of the solar generator can be connected to $\mathrm{N}$ if all power semiconductors are connected in opposite direction.

Fig. 2 shows the switching states of the inverter section, which are chosen by a pulse with modulation (see also [5-7]). During the positive half-wave, the switching states 1 and $3 a$

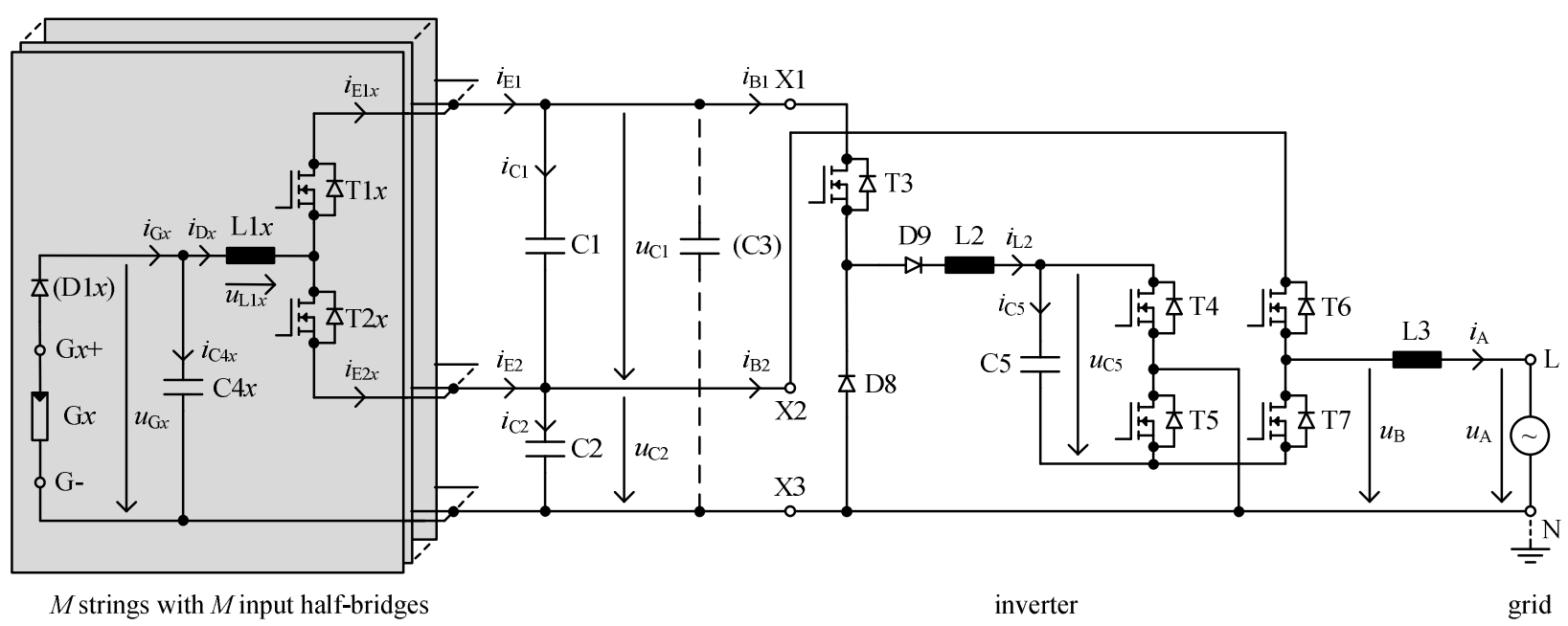

Fig. 1: The new inverter circuit (see also [4]) 


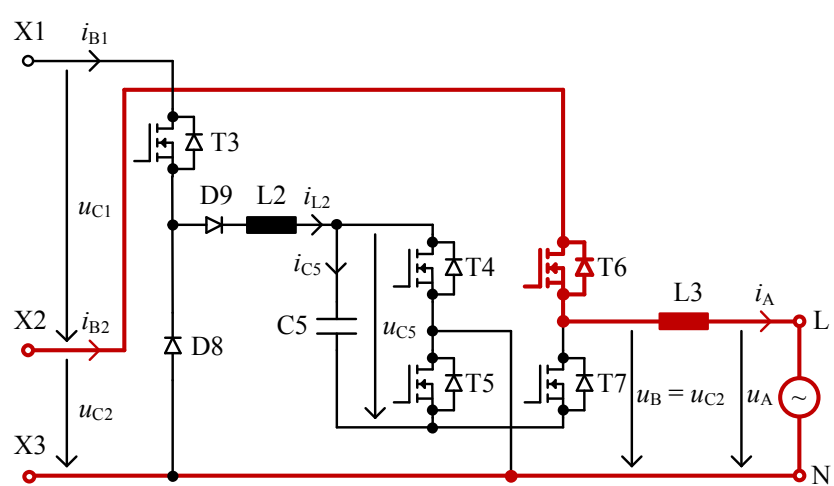

State 1 (positive half-wave)

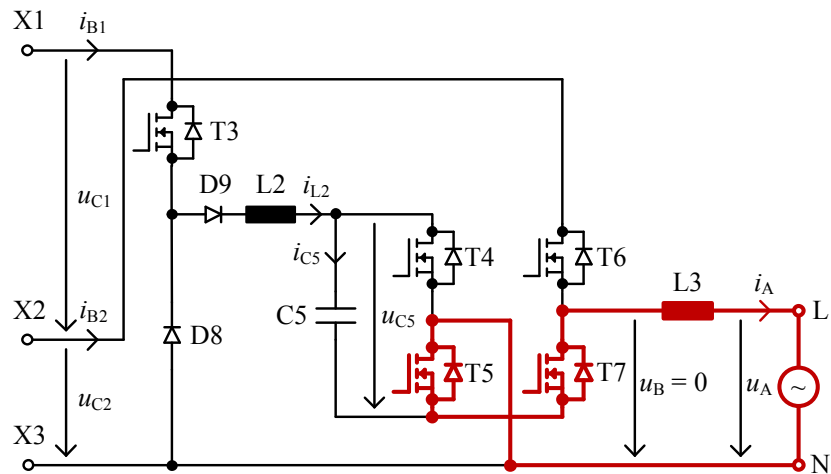

State $3 a$ (positive half-wave)

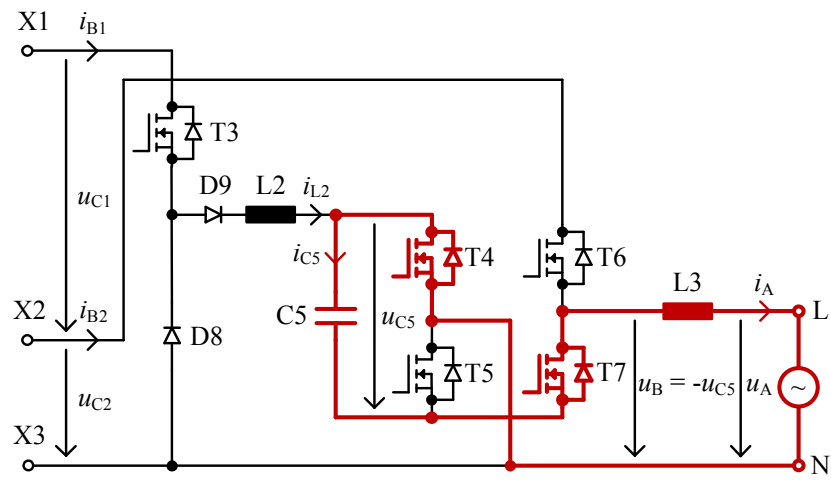

State 2 (negative half-wave)

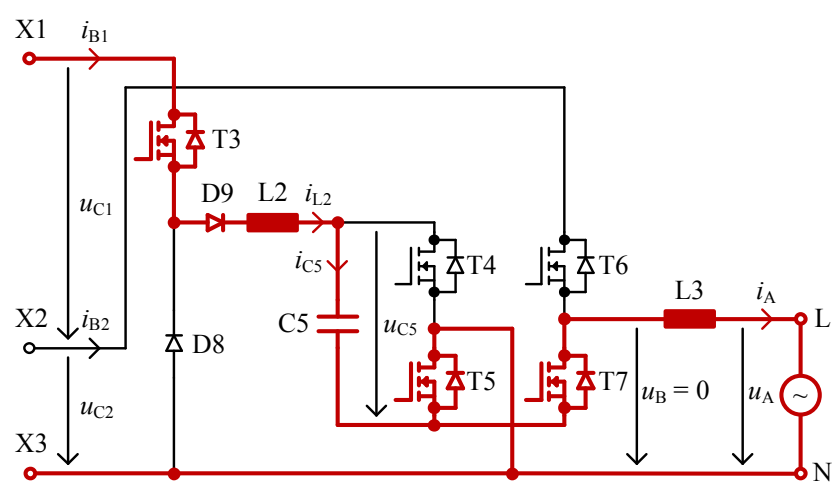

State $3 b$ (negative half-wave)

Fig. 2: Switching states (see also [5-7]) are used alternately. This operation mode is similar to a buck converter. The state durations depend on the set value $u_{\mathrm{B}}$ :

$$
T_{1}=\frac{1}{f_{\mathrm{sw}}} \cdot \frac{u_{\mathrm{B}}^{\prime}}{u_{\mathrm{C} 2}} \quad T_{3 \mathrm{a}}=\frac{1}{f_{\mathrm{sw}}} \cdot\left(1-\frac{u_{\mathrm{B}}^{\prime}}{u_{\mathrm{C} 2}}\right)
$$

During the negative half-wave, the switching states 2 and $3 \mathrm{~b}$ are used alternately. In state 2 , the voltage $u_{\mathrm{C} 5}$ of the flying capacitor $\mathrm{C} 5$ is applied to the $\mathrm{AC}$ side and $\mathrm{C} 5$ gets discharged. In the free-wheeling state $3 \mathrm{~b}, \mathrm{C} 5$ is recharged resonantly via T3, D9, L2 and T5. The durations of the switching states are as follows:

$$
T_{2}=\frac{1}{f_{\mathrm{sw}}} \cdot \frac{-u_{\mathrm{B}}^{\prime}}{u_{\mathrm{C} 5}} \quad T_{3 \mathrm{~b}}=\frac{1}{f_{\mathrm{sw}}} \cdot\left(1-\frac{-u_{\mathrm{B}}^{\prime}}{u_{\mathrm{C} 5}}\right)
$$

The resonant charging process is shown in Fig. 3 (see also [5-7]). The charging current $i_{\mathrm{L} 2}$ is switched off by the diode D9 at a value of zero. The diode D8 protects the transistor T3 from overvoltage, if T3 switched off, before $i_{\mathrm{L} 2}$ has reached zero [4]. Due to parasitic resistances in the charging path, the current $i_{\mathrm{L} 2}$ is a damped sine half-wave (see also [7,8]). Note, that the energy for the positive half-wave of $u_{\mathrm{A}}$ is taken from $\mathrm{X} 2$ / X3, while the energy for the negative half-wave is taken from X1 / X3 [4].
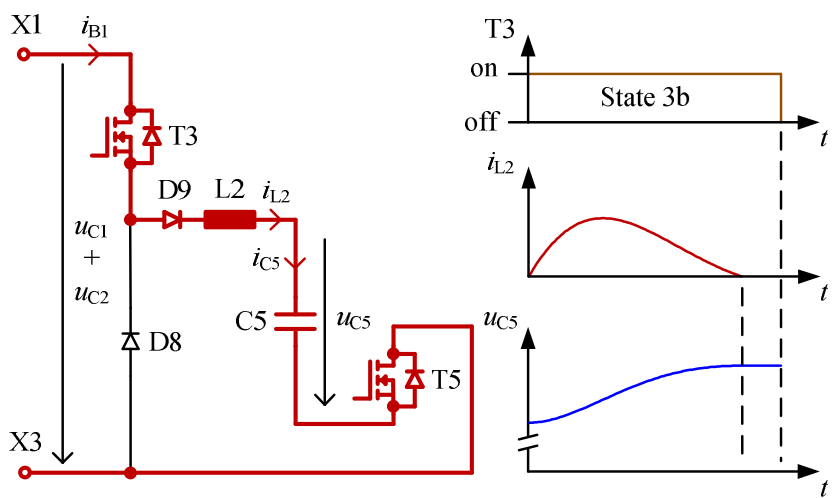

Fig. 3: Resonant charging process (see also [5-7])

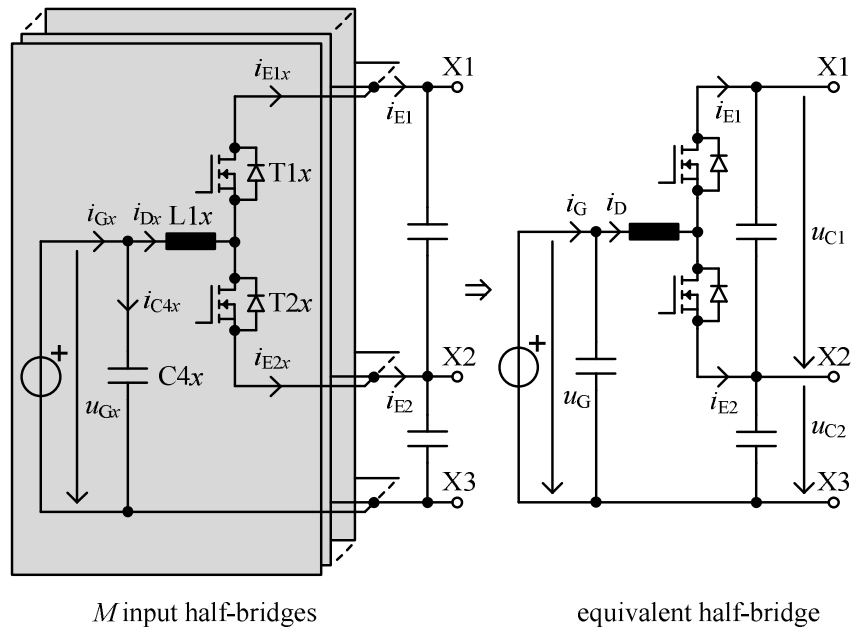

Fig. 4: Equivalent input section (see also [9]) 
The input section, consisting of $M$ half-bridges, can be modelled as one equivalent half-bridge according to Fig. 4 (see also [9]). The equivalent currents $i_{\mathrm{G}}$ and $i_{\mathrm{D}}$, as well as the equivalent voltage $u_{\mathrm{G}}$ are calculated as follows [9]:

$$
\begin{array}{ll}
i_{\mathrm{G}}=\sum_{x=1}^{M} i_{\mathrm{G} x} & i_{\mathrm{D}}=\sum_{x=1}^{M} i_{\mathrm{D} x} \\
u_{\mathrm{G}}=\frac{\sum_{x=1}^{M} u_{\mathrm{G} x} \cdot i_{\mathrm{G} x}}{i_{\mathrm{G}}} &
\end{array}
$$

The transistors T $1 x$ and T2x are controlled by a pulse width modulation. They split the input currents $i_{\mathrm{G} x} \approx i_{\mathrm{D} x}$ into the currents $i_{\mathrm{E} 1 x}$ and $i_{\mathrm{E} 2 x}$ (Fig. 4). These currents sum up to $i_{\mathrm{E} 1}$ and $i_{\mathrm{E} 2}$. Neglecting losses, their mean values per pulse-period $\bar{i}_{\mathrm{E} 1}$ and $\bar{i}_{\mathrm{E} 2}$ are calculated with the mean current per pulse-period $\bar{i}_{\mathrm{D}}$ (see also [10]):

$$
\begin{aligned}
& \bar{i}_{\mathrm{E} 1}=\frac{u_{\mathrm{G}}-u_{\mathrm{C} 2}}{u_{\mathrm{C} 1}} \cdot \bar{i}_{\mathrm{D}} \\
& \bar{i}_{\mathrm{E} 2}=\left(1-\frac{u_{\mathrm{G}}-u_{\mathrm{C} 2}}{u_{\mathrm{C} 1}}\right) \cdot \bar{i}_{\mathrm{D}}
\end{aligned}
$$

The mean input currents per grid-period of the inverter section depend on the active power $P_{\mathrm{A}}$ delivered to the grid. Assuming, that $u_{\mathrm{C} 1}=\bar{u}_{\mathrm{C} 1}$ and $u_{\mathrm{C} 2}=\bar{u}_{\mathrm{C} 2}$ are constant, they can be calculated as follows (see also [10]):

$$
\begin{aligned}
& \bar{i}_{\mathrm{B} 1}=\frac{1}{2} \cdot \frac{P_{\mathrm{A}}}{\bar{u}_{\mathrm{C} 1}+\bar{u}_{\mathrm{C} 2}} \\
& \bar{i}_{\mathrm{B} 2}=\frac{1}{2} \cdot \frac{P_{\mathrm{A}}}{\bar{u}_{\mathrm{C} 2}}
\end{aligned}
$$

In stationary operation, the mean values of the capacitor currents $i_{\mathrm{C} 1}$ and $i_{\mathrm{C} 2}$ shall be zero. This leads to [10]:

$$
\bar{i}_{\mathrm{B} 1}=\bar{i}_{\mathrm{E} 1} \quad \bar{i}_{\mathrm{B} 2}=\bar{i}_{\mathrm{E} 2}
$$

The mean capacitor current $\bar{i}_{\mathrm{C} 2}$ and therefore the voltage at the capacitor $\mathrm{C} 2$ (Fig. 1) can be controlled with the active power component $P_{\mathrm{A}}$ of the inverter section. Due to a natural balancing effect, the mean voltage $\bar{u}_{\mathrm{C} 1}$ at the capacitor $\mathrm{C} 1$ automatically reaches a stable value under the following conditions [10]:

$$
\begin{aligned}
& \frac{1}{2} \cdot u_{\mathrm{G}}<u_{\mathrm{C} 2}<u_{\mathrm{G}} \quad \mid \quad u_{\mathrm{C} 1}+u_{\mathrm{C} 2}>u_{\mathrm{G}} \\
& \bar{i}_{\mathrm{D}}>0
\end{aligned}
$$

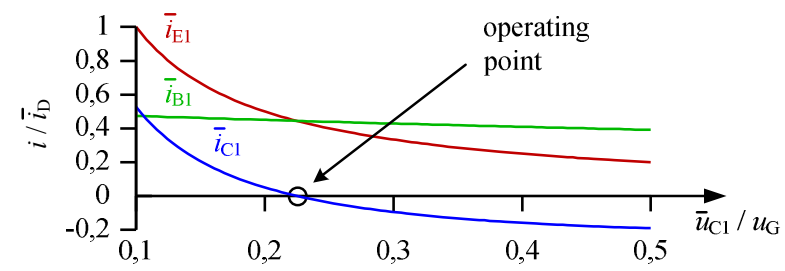

Fig. 5: Capacitor current $\bar{i}_{\mathrm{C} 1}$ over capacitor voltage $\bar{u}_{\mathrm{C} 1}$
Fig. 5 shows a graphical example for $\bar{u}_{\mathrm{C} 2}=0.9 \cdot u_{\mathrm{G}}$ and $\bar{i}_{\mathrm{C} 2}=0$. The capacitor current $\bar{i}_{\mathrm{C} 1}=\bar{i}_{\mathrm{E} 1}-\bar{i}_{\mathrm{B} 1}$ crosses zero at the following operating point [10]:

$$
\bar{u}_{\mathrm{C} 1}=\frac{2 \cdot\left(u_{\mathrm{G}}-\bar{u}_{\mathrm{C} 2}\right) \cdot \bar{u}_{\mathrm{C} 2}}{2 \cdot \bar{u}_{\mathrm{C} 2}-u_{\mathrm{G}}} \quad \text { for } \quad \frac{1}{2} \cdot u_{\mathrm{G}}<\bar{u}_{\mathrm{C} 2}<u_{\mathrm{G}}
$$

The capacitors $\mathrm{C} 1$ and $\mathrm{C} 2$ buffer the pulsating energy, that occurs due to the usage of a single-phase inverter section [4]. Therefore, the voltages $u_{\mathrm{C} 1}$ and $u_{\mathrm{C} 2}$ are pulsating. The amplitudes of the pulsations around the operating points $\bar{u}_{\mathrm{C} 1}$ and $\bar{u}_{\mathrm{C} 2}$ depend on the capacitance values of $\mathrm{C} 1$ and $\mathrm{C} 2$, as well as on the apparent power at the AC-side [10]. Generally, the capacitor voltages have to fulfill the following conditions:

$$
\begin{aligned}
& \hat{U}_{\mathrm{B}}<u_{\mathrm{C} 2}<u_{\mathrm{G}, \min } \\
& u_{\mathrm{G}, \max }<u_{\mathrm{C} 1}+u_{\mathrm{C} 2}
\end{aligned}
$$

$\hat{U}^{\prime}{ }_{\mathrm{B}}$ is the amplitude of the set value $u_{\mathrm{B}}$ at the AC-side. The values $u_{\mathrm{G}, \min }$ and $u_{\mathrm{G}, \max }$ are the minimum and maximum voltages of the different strings at their maximum power point (see example in Fig. 6). It is advantageous to keep $u_{\mathrm{C} 1}$ as low as possible. This reduces the switching losses in the input half-bridges and allows the usage of small input inductors L1x [10]. A low value of $\bar{u}_{\mathrm{C} 1}$ is achieved by choosing a high reference value for $\bar{u}_{\mathrm{C} 2}$ (see eq. (12)).

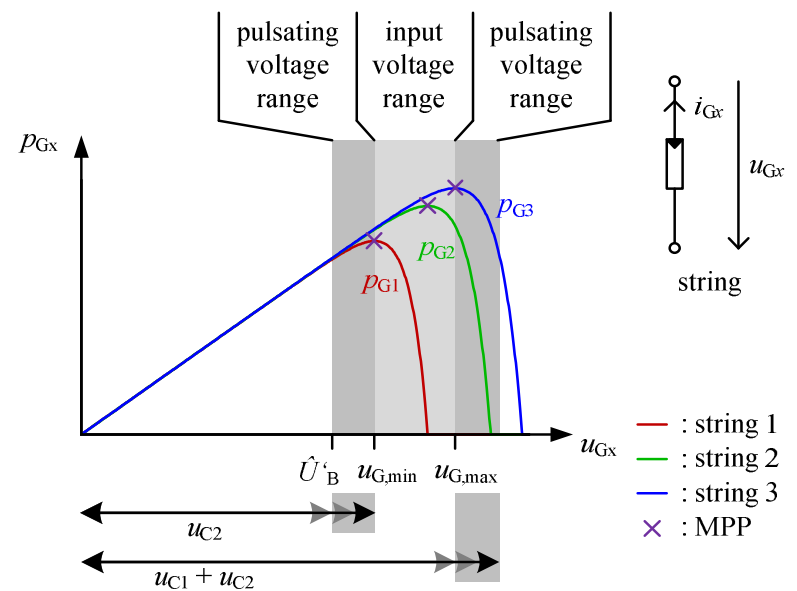

Fig. 6: voltage ranges; model parameters are taken from Table 2 of [11]

The transistors $\mathrm{T} 1 x$ and $\mathrm{T} 2 x$ only have to block voltages in the range of the maximum voltage at the capacitor $\mathrm{C} 1$, which is usually a fraction of the input voltages $u_{\mathrm{G} x}$. Therefore, T1x, $\mathrm{T} 2 x$ and $\mathrm{C} 1$ can be dimensioned for a fraction of $u_{\mathrm{G} x}$. This leads to low losses and low costs. However, measures against overvoltage of $u_{\mathrm{C} 1}$ have to be taken. For example, overvoltage due to external short circuits at one of the strings can be prevented by additional diodes D1 $x$ (Fig. 1). [4]

The circuit of Fig. 1 could also be realized with three inverter sections, connected in parallel to X1-X3. This allows an operation at three-phase grids. 


\section{Cascaded control scheme}

The circuit contains $2 M+5$ components, that store energy:

- $\quad M$ input capacitors $\mathrm{C} 4 x$

- $M$ inductors L1x

- Capacitor C1

- Capacitor C2

- Charging inductor L2

- Flying capacitor C5

- $\mathrm{AC}$ inductor L3

A cascaded control scheme is proposed. It requires, that the following values are measured:

- $\quad M$ input voltages $u_{\mathrm{G} x}$

- $\quad M$ inductor currents $i_{\mathrm{D} x}$

- Capacitor voltage $u_{\mathrm{C} 1}$

- $\quad$ Capacitor voltage $u_{\mathrm{C} 2}$

- $\quad$ Flying capacitor voltage $u_{\mathrm{C} 5}$

- $\quad$ AC voltage $u_{\mathrm{A}}$

- $\quad \mathrm{AC}$ current $i_{\mathrm{A}}$

As the charging current $i_{\mathrm{L} 2}$ for the flying capacitor C5 is automatically switched off at a value of zero, there is no need to measure that current (see also [6]). The control scheme requires the following reference values:

- $\quad M$ reference input voltages $u_{\mathrm{G} x, \mathrm{w}}^{\prime}$

- Reference capacitor voltage $u^{\prime}{ }^{2}$,, $\mathrm{w}$

The currents $i_{\mathrm{D} x}$ at the inductors $\mathrm{L} 1 x$ are set with $M$ underlying control loops according to Fig. 7. Values, that occur physically are drawn in blue. Values that occur in the control system, are drawn in red and marked with an apostrophe ('). All values are mean values during one pulse-

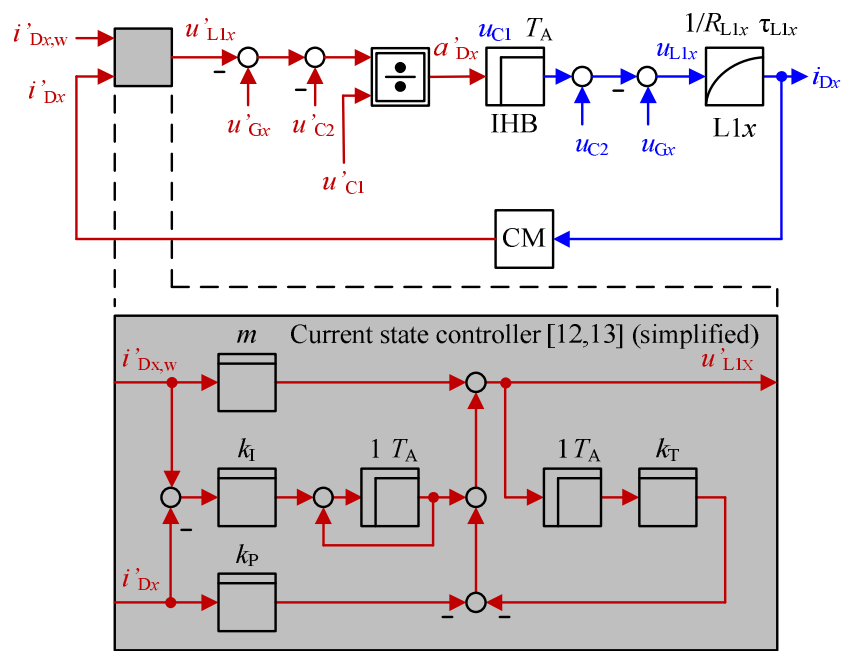

IHB: input half-bridge

CM: current measurement

Fig. 7: Underlying control structure for the inductor currents $i_{\mathrm{D} x}$ period. The inductors L1 $x$ are modeled as first order lag elements, which allows the consideration of a series resistance. A dead time of $T_{\mathrm{A}}$ occurs due to the pulse width modulation of the input half-bridges with the duty cycle $a_{\mathrm{D} x}$. For high dynamic capabilities, state controllers according to $[12,13]$ are used. Controller parameters can be found in [13]. The voltages $u_{\mathrm{G} x}, u_{\mathrm{C} 1}$ and $u_{\mathrm{C} 2}$ are measured and fed-forward.

The inductor currents $i_{\mathrm{D} x}$ are used to set the $M$ input voltages $u_{\mathrm{G} x}$ in an overlying control loop (Fig. 8, see also [9]). For this purpose, standard PI-controllers are sufficient. Controller parameters can be calculated according to the symmetrical optimum [12]. The reference values $u_{\mathrm{G} x, \mathrm{w}}$ are set by standard MPP tracking algorithms, e.g. by perturb and observe algorithms.

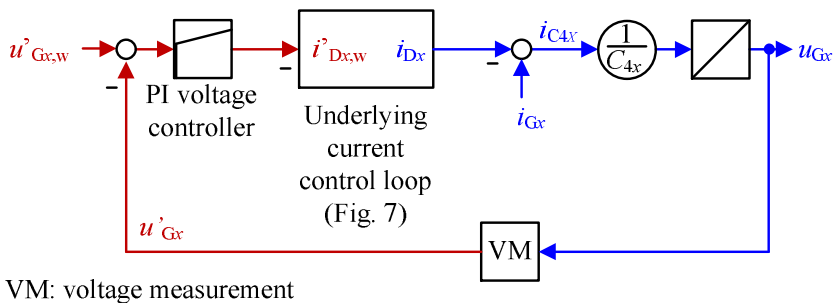

Fig. 8: Overlying control structure for the input voltages $u_{\mathrm{G} x}$ (see also [9])

The AC current $i_{\mathrm{A}}$ is controlled in an underlying loop, that sets the switching states from Fig. 2 . The amplitude $\hat{I}_{\mathrm{A} \text {,w }}$ of the AC current depends on the reference value $P^{\prime}{ }_{\mathrm{A}, \mathrm{w}}$ of the active power component and on the desired phase shift $\varphi^{\prime}{ }_{\text {UI }}$ between voltage and current (Fig. 9).

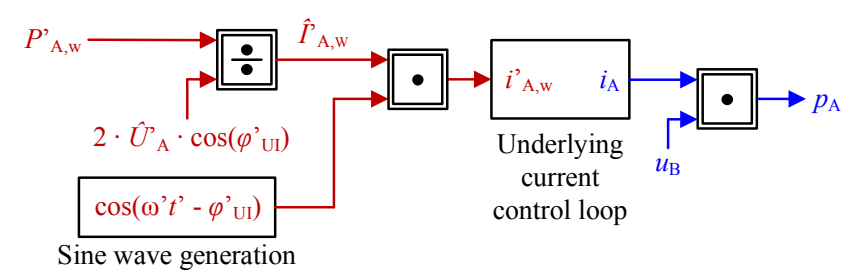

Fig. 9: Calculation of the reference AC current $i_{\mathrm{A}, \mathrm{w}}$

The current $i_{\mathrm{C} 2}$ at the capacitor $\mathrm{C} 2$ equals the difference between the sum input current $i_{\mathrm{D}}$ and the sum of the currents $i_{\mathrm{B} 1}$ and $i_{\mathrm{B} 2}$ at the inverter section:

$$
i_{\mathrm{C} 2}=i_{\mathrm{D}}-i_{\mathrm{B} 1}-i_{\mathrm{B} 2}
$$

The mean inverter input currents during one pulse-period depend on the instantaneous power $p_{\mathrm{A}}$ at the AC side:

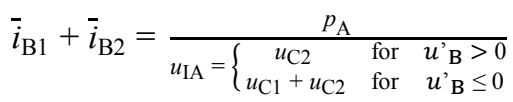

Therefore, the voltage at $\mathrm{C} 2$ can be set with the active power component $P_{\mathrm{A}}$ in an overlying control loop according to Fig. 10 . The ripple on the measured value $u_{\mathrm{C} 2}$ is suppressed by a moving average filter with an averaging time of 
$T_{\mathrm{MA}}=1 / f_{\text {grid. }}$. The sum of the reference input currents $i_{\mathrm{D}, \mathrm{w}}=\sum_{x=1}^{M} i_{\mathrm{D} x \mathrm{w}}$ is smoothened by another moving average filter and fed-forward.

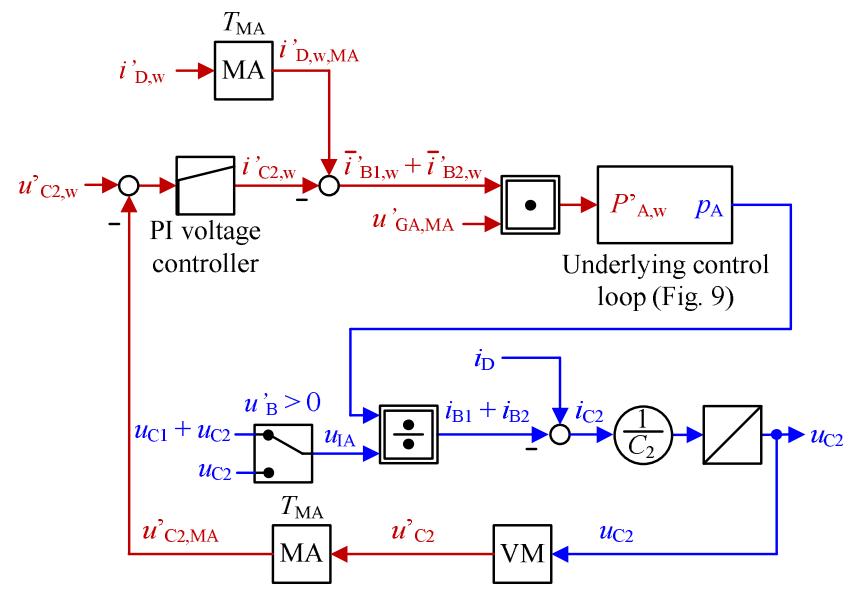

MA: moving average filter

Fig. 10: Overlying control structure for the capacitor voltage $u_{\mathrm{C} 2}$

The reference value $P^{\prime}{ }_{\mathrm{A}, \mathrm{w}}$ is finally calculated with:

$$
\begin{gathered}
P_{\mathrm{A}, \mathrm{w}}^{\prime}=\left(i_{\mathrm{D}, \mathrm{w}, \mathrm{MA}}-i_{\mathrm{C} 2, \mathrm{~W}}^{\prime}\right) \cdot u_{\mathrm{GA}, \mathrm{MA}}^{\prime} \\
u_{\mathrm{GA}, \mathrm{MA}}^{\prime}=\frac{2 \cdot u_{\mathrm{C} 2, \mathrm{MA}}^{\prime} \cdot\left(u_{\mathrm{C} 1, \mathrm{MA}}^{\prime}+u_{\mathrm{C} 2, \mathrm{MA}}^{\prime}\right)}{2 \cdot u_{\mathrm{C} 2, \mathrm{MA}}+u_{\mathrm{C} 1, \mathrm{MA}}^{\prime}}
\end{gathered}
$$

$u_{\mathrm{GA}, \mathrm{MA}}$ is a kind of mean value of $u_{\mathrm{IA}}$. It can be calculated with the averaged voltages $u_{\mathrm{C} 1, \mathrm{MA}}^{\prime}$ and $u_{\mathrm{C} 2 \mathrm{MA}}^{\prime}$ at the capacitors $\mathrm{C} 1$ and $\mathrm{C} 2$. Moving average filters with $T_{\mathrm{MA}}=1 / f_{\text {grid }}$ suppress the ripples, caused by the pulsating power at the AC side (Fig. 11).

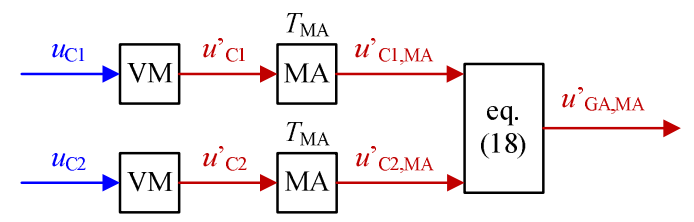

Fig. 11: Calculation of $u_{\mathrm{GA}, \mathrm{MA}}$

\section{Experimental results}

A modular $3.7 \mathrm{~kW}$ prototype for a grid voltage of $230 \mathrm{~V}$ has been built up. Fig. 12a) shows a printed circuit board (PCB) with two input half-bridges. Fig. 12b) shows the PCB with the inverter section. Values and names of important components are listed in Table 1. The input half-bridges, consisting of T1x and $\mathrm{T} 2 x$, are built up with low voltage silicon MOSFETs. Their $R_{\mathrm{DS}(\text { on) }}$ is only $32 \mathrm{~m} \Omega$, which leads to low losses. The inverter section is built up with silicon carbide MOSFETs. As the voltage at the transistor T6 can be approximately twice as high as the voltages at T3-T5 and T7, two MOSFETs are connected in series (see also [4]). A small film capacitor C3 is added to provide a current path with low inductance between $\mathrm{X} 1$ and $\mathrm{X} 3$.

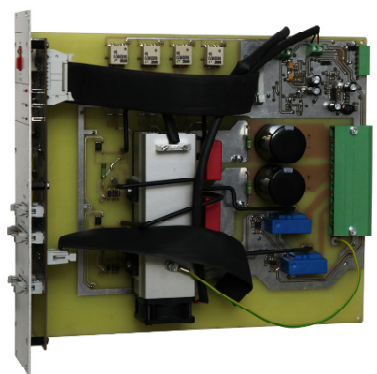

b)

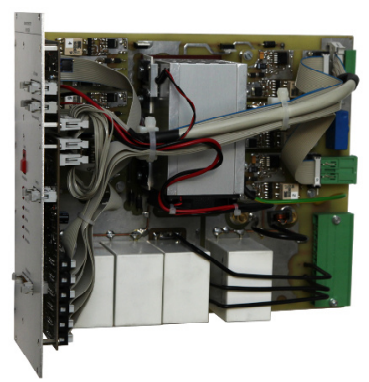

Fig. 12: Prototype printed circuit boards

\begin{tabular}{|l|l|l|}
\hline Component & Value / Part Name & Comment \\
\hline T1 $x, \mathrm{~T} 2 x$ & Infineon IPP320N20N3G & $\begin{array}{l}U_{\mathrm{DSmax}}=200 \mathrm{~V} \\
I_{\mathrm{D} @ 100^{\circ} \mathrm{C}}=22 \mathrm{~A}\end{array}$ \\
\hline T3, T5 & CREE C2M0025120D & $\begin{array}{l}U_{\mathrm{DSmax}}=1200 \mathrm{~V} \\
I_{\mathrm{D} @ 100^{\circ} \mathrm{C}}=60 \mathrm{~A}\end{array}$ \\
\hline T4, T7 & CREE C2M0040120D & $\begin{array}{l}U_{\mathrm{DSmax}}=1200 \mathrm{~V} \\
I_{\mathrm{D} @ 100^{\circ} \mathrm{C}}=40 \mathrm{~A}\end{array}$ \\
\hline T6 & $\begin{array}{l}\text { 2x CREE C2M0040120D } \\
\text { in series }\end{array}$ & $\begin{array}{l}U_{\mathrm{DSmax}}=1200 \mathrm{~V} \\
I_{\mathrm{D} @ 100^{\circ} \mathrm{C}}=40 \mathrm{~A}\end{array}$ \\
\hline D9 & IXYS DSEI60-02A & $\begin{array}{l}U_{\mathrm{RRM}}=200 \mathrm{~V} \\
I_{\mathrm{FAVM} @ 85^{\circ} \mathrm{C}}=69 \mathrm{~A}\end{array}$ \\
\hline C1 & $8850 \mu \mathrm{F} / 160 \mathrm{~V}$ & $\begin{array}{l}\text { Electrolytic }+ \\
\text { Film }\end{array}$ \\
\hline C2 & $450 \mu \mathrm{F} / 900 \mathrm{~V}$ & Film \\
\hline C3, C4x, & $50 \mu \mathrm{F} / 900 \mathrm{~V}$ & Film \\
C5 & $720 \mu \mathrm{H}$ & \\
\hline L1x & $\begin{array}{l}\text { Coilcraft SER2011- } \\
\text { L2 }\end{array}$ & $\begin{array}{l}+ \text { additional } \\
\text { parasitic } \\
\text { inductance }\end{array}$ \\
\hline L3 & $5 \mathrm{ML}$ (500nH) & \\
\hline
\end{tabular}

Table 1: Values and names of components

Fig. 13 shows corresponding measurement results. The investigated prototype is equipped with three DC inputs. All three strings were replaced by a single $620 \mathrm{~V}$ laboratory power supply. Every input $\mathrm{G} x+$ is connected with a series resistance of $50 \Omega$ to the plus pole of the power supply. The AC-side is connected to the $230 \mathrm{~V} / 50 \mathrm{~Hz}$ grid. The switching frequency of the inverter section is set to $12 \mathrm{kHz}$, while the switching frequency of the input half-bridges is set to $24 \mathrm{kHz}$. The power at the AC-side is $P_{\mathrm{A}}=3.7 \mathrm{~kW}$. Additional measures against wind-up are taken in all controllers.

The first two plots show the grid voltage $u_{\mathrm{A}}$ and the grid current $i_{\mathrm{A}}$, which is controlled sinusoidally. The power factor is set to $\cos \left(\varphi_{\mathrm{UI}}\right)=1$. The three input voltages $u_{\mathrm{G} x}$ in the third plot are held constant by the control system. The voltages $u_{\mathrm{C} 2}$ and $u_{\mathrm{C} 1}+u_{\mathrm{C} 2}$ are pulsating due to the single phase conversion. A high ripple on these voltages is permissible, which allows the usage of small film capacitors $\mathrm{C} 2$ and $\mathrm{C} 3$. The voltage $u_{\mathrm{C} 5}$ of the flying capacitor $\mathrm{C} 5$ is overlayed with a $12 \mathrm{kHz}$ ripple during the negative half-wave of $u_{\mathrm{A}}$. The forth plot shows the currents $i_{\mathrm{D} x}$ at the inductors $\mathrm{L} 1 x$, that were sampled by the control system. The current ripple at one of the inductors L1x 
can be seen in the fifth plot, as this measurement was taken with an oscilloscope. The proposed control structure leads to a stable system.
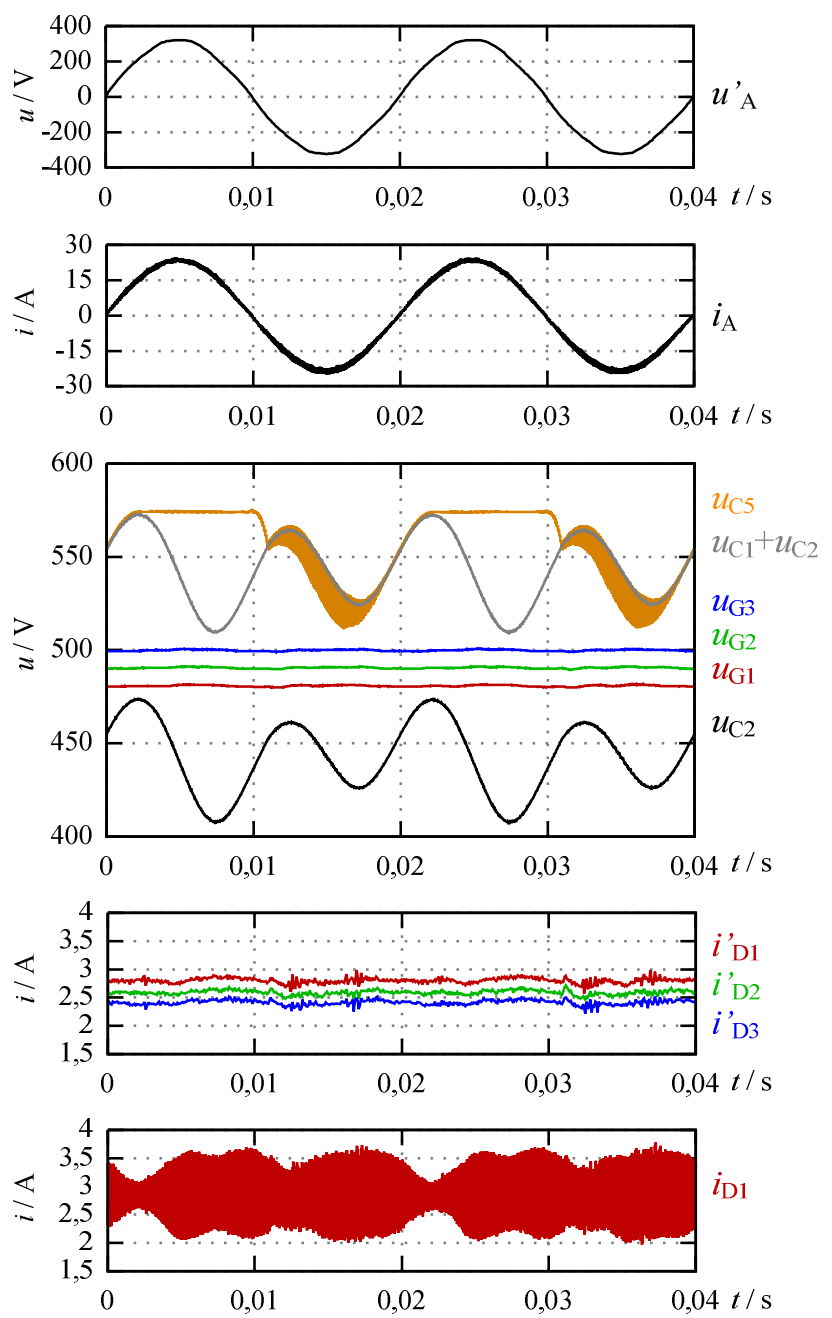

Fig. 13: Experimental results; Values with apostrophe (') are sampled values of the control system; Values without apostrophe are measured with an oscilloscope

\section{Conclusion}

A new transformerless photovoltaic inverter circuit is described in detail. It allows an individual MPP tracking of several strings, without needing a full scale boost converter for each string. Either the plus-poles or the minus-poles of all strings are connected to the neutral conductor $\mathrm{N}$. Therefore, it is especially suited for thin-film or back-side contacted solar modules. The circuit generates a three level output voltage and is capable of delivering reactive power. An appropriate control scheme is presented. Experimental results proof the proper function of the circuit and of the control system.

\section{References}

[1] C. Osterwald, T. McMahon, and J. del Cueto, "Electrochemical corrosion of $\mathrm{SnO}_{2}: \mathrm{F}$ transparent conducting layers in thin-film photovoltaic modules", Solar Energy Materials \& Solar Cells, vol. 79, 2003.

C. Ackermann, "Optimale Regelung der permanentmagneterregten Synchronmaschine unter Nutzung des Reluktanzmoments", von der Fakultät für Elektrotechnik und Informationstechnik des Karlsruher Instituts für Technologie (KIT) genehmigte Dissertation, 2012. 